\title{
A Study on Mechanical Properties of Aluminium Alloy (Lm6) Reinforced With Fly Ash, Redmud and Silicon Carbide
}

\author{
Mr.Vijay Kumar S Maga ${ }^{1}$, B S Motagi ${ }^{2}$ \\ ${ }^{I}$ Post Graduate Student, Department of Mechanical Engineering, PDA College of Engineering and Technology, \\ Gulbarga Karnataka, India \\ ${ }^{2}$ Associate Professor,Mechanical Engineering Dept., PDA College of Engineering and Technology, Gulbarga,
} Karnataka, India

\begin{abstract}
This work deals with fabricating or producing aluminium based metal matrix composite and thenstudying its microstructure and mechanical properties such as tensile strength, impact strength and wear behavior of produced test specimen. In this present study a modest attempt has been made to develop aluminium based MMCs with reinforcing material with an objective to develop a conventional low cast method of producing MMCs and to obtain homogeneous dispersion of reinforced material. To achieve this objective stir casting technique has been adopted. Aluminium Alloy (LM6) and Sic, Fly Ash, Red mud has been chosen as matrix and reinforcing material respectively. Experiment has been conducted by varying weight fraction of Sic, Fly Ash, Redmud. The result shown that the increase in addition of Fly Ash is giving better result when compared with Redmud.
\end{abstract}

Keywords: Fly Ash (F.A.), Redmud(R.M.), Hybrid Composites, Silicon Carbide, stir casting.

\section{Introduction}

Aluminum alloys are broadly used as a main matrix element in composite materials. Aluminum alloys for its light weight, has been in the net of researchers for enhancing the technology. The broad use of aluminum alloys is dictated by a very desirable combination of properties, combined with the ease with which they may be produced in a great variety of forms and shapes[3].

Now a day the light weight composite material are widely used in engineering field. The composite material has good characteristic of hardness, resisting wear resistance and tensile strength due to good strength and less weight the composite material play a vital role in engineering field.

Discontinuously reinforced aluminium matrix composites are fast emerging as engineering materialsand competing with common metals and alloys. They are gaining significant acceptance because of higherspecific strength, specific modulus and good wear resistance as compared to ordinary unreinforced alloys.Reinforcing particles used in this study are silicon carbide, fly ash and Red mud particles which are added externally [1].

Aluminium alloy (LM6) is used in Marine, Automobile, Aerospace industries. One of the main drawbacks of this material system is that they exhibit poor tribological properties.Hence the desire in theengineering community to develop a new material with greater wear resistance and better tribological properties [1].

Silicon carbide is a compound of silicon and carbon with a chemical formula Sic. Silicon carbide wasoriginally produced by a high temperature electrochemical reaction of sand and carbon. Silicon carbide ceramics with little or no grain boundary impurities maintain their strength to very high temperatures, approaching $1600^{\circ} \mathrm{C}$ with no strength loss. It is an excellent abrasive and has been produced and made into grinding wheels and other abrasive products for over one hundred years. Today the material has been developed into a high quality technical grade ceramic with very good mechanical properties. It is used in abrasives, refractory's,ceramics and numerous high-performance applications [1].

Fly ash is one of the most inexpensive and low density reinforcement available in large quantities assolid waste by-product during combustion of coal in thermal power plants.Coal Combustion Products (CCP) isproduced in coal-fired power stations, which burn either hard or brown coal. Due to the mineral component ofcoal and combustion technique, Fly Ash (FA) is produced. The utilization of fly ash instead of dumping it as awaste material can be both on economic and environmental grounds. There is already a vast body of information on utilization of Fly Ash (FA) in building/construction, production of aggregates and more recently for agriculture $[1,4]$.

Composites are engineered or naturally occurring materials made from two or more constituentmaterials with significantly different physical or chemical properties that remain separate and distinct within thefinished structure. The bulk material forms the continuous phase that is the matrix (e.g., metals, polymers) and the other acts as the discontinuous phase that is the reinforcements (e.g., ceramics, fibers, 
whiskers, particulates). While the reinforcing material usually carries the major amount of load, the matrix enables theload transfer by holding them together [2].

\section{A Study on Mechanical Properties of Aluminium Alloy (LM6) Reinforced with Sic Fly Ash and Red mud}

The challenges and opportunities of aluminium matrix composites have been reported much better to that of its unreinforced counterpart. The addition of reinforcing phase significantly improves the tribological properties of aluminium and its alloy system. The thinking behind the development of hybrid metal matrix composites is to combine the desirable properties of aluminium, silicon carbide and fly ash. Aluminium have useful properties such as high strength, ductility, high thermal and electrical conductivity but have low stiffness whereas silicon carbide fly ash and Red mud are stiffer and stronger and have excellent high temperature resistance but they are brittle in nature[1,5].

In this study an attempt has been made to fabricate a Hybrid Composite from commercial silicon carbide fly ash and Red mud. Aluminium alloy (LM6) is used as matrix material for the fabrication of LM6-Sicfly ash and LM6-Sic-Red mud hybrid composite material. Methods available for the production of Hybrid Composites are powder metallurgy, spray deposition, liquid metal infiltration, squeeze-casting, stir-casting. Though various processing techniques available for particulate or discontinuous reinforced metal matrix composites, stir casting is the technique, which is in use for large quantity commercial production. This technique is most suitable due to its simplicity, flexibility and ease of production for large sized components. Hence stir casting method is used in this study [6].

The objective of present work is to produce hybrid composites of LM6/Sic/fly ash and LM6/Sic/Red mud by stir casting method. And determine the effect of addition of fly ash and red mud on mechanical and tribological properties of LM6-silicon carbide MMCs.

\section{Materials And Method}

\section{Materials}

The materials used in this present investigation are LM6, Sic, Fly Ash and red mud. Here the grain size of the Sic(black) is $37 \mu \mathrm{m}$ Fly Ash (brown) is $100 \mu$ mand Red mud (red)is $100 \mu \mathrm{m}$. Chemical composition of LM6 with Fly Ash and Redmud is given in Table 1,2 and 3

\section{Experimental Methodology}

The metal matrix composite used in the study was prepared out by stir casting method. A stir casting setup, Consisted of a Induction Furnace and a stainless Steel stirrer assembly, was used to synthesize the composite. The stirrer assembly consisted of a stirrer, which was connected to a variable speed vertical motor of $400 \mathrm{rpm}$ by means of a steel shaft. The stirrer was made by cutting and shaping a Stainless Steel block to desired shape and size manually. Graphite crucible of $1.5 \mathrm{Kg}$ capacity was placed inside the furnace. The graphical representation of stir casting was shown in Fig.1.

LM6 (Aluminium) was melted at $720^{\circ} \mathrm{C}$ in the Induction furnace. Preheating of reinforcement (Fly Ash at $350^{\circ} \mathrm{C}$, silicon carbide at $350^{\circ} \mathrm{C}$, Red mud $350^{\circ} \mathrm{C}$ ) was done for one hour to remove moisture and gases from the surface of the particulates. The stirrer was then lowered vertically up to $3 \mathrm{~cm}$ from the bottom of the crucible. The speed of the stirrer was gradually raised to $400 \mathrm{rpm}$ and the preheated reinforced particles were added into the melt. The speed controller maintained a constant speed of the stirrer, as the stirrer speed got reduced by $100 \mathrm{rpm}$ due to the increase in viscosity of the melt when particulates were added into the melt. After the addition of reinforcement, stirring was continued for 4 to 6 minutes for proper mixing of prepared particles in the matrix. The melt was kept in the crucible for approximate half minute in static condition and then it was poured in the die. The value of the SiCFly Ash and Red mud varied by $3 \%$ \& 6\%. By this process eight sets of specimens were prepared for each test. The test are carried out such as tensile, impact and wear. The microstructures of all the sample are studied.

\section{Microstructure Analysis}

\section{Result And Discussion}

The morphology, density, type of reinforcing particles and its distribution have a major influence on the properties of particulate composites. The variables that govern the distribution of particles are solidification rate, fluidity, type of reinforcement and the method of incorporation. It is necessary to distribute particles uniformly throughout the casting during production of particulate composites. The first task is to get a uniform distribution of particles in the liquid melt and then to prevent segregation/agglomeration of particles during pouring and progress of solidification [2].After going through the microstructure study of each different composites obtained which shows that the reinforcement are distributed near uniformly in a LM6 metal matrix composite(MMC). 


\section{Tensile Test}

A Study on Mechanical Properties of Aluminium Alloy (LM6) Reinforced with Sic and Fly Ash Tensile test is carried out at room temperature using universal testing machine. In this study it can be noted that the addition of Sic and Fly Ash particles improved the tensile strength of the composites. It is apparent that an varying in the volume fraction of Sic,Flyash particle results in an increase in the tensile strength [6]. Graph1, graph 2 and graph 4,graph 5shows the effect of the weight fraction on the tensile strength and graph 3 and graph 6 shows the percentage of elongation. The tensile strength of Sample2(LM6+3\% $\mathrm{SiC}+3 \% \mathrm{~F}$.A.) is 165.358 $\mathrm{N} / \mathrm{mm}^{2}$ and this value increases to a maximum of $174.097 \mathrm{~N} / \mathrm{mm}^{2}$ for Sample3 (LM6 $+3 \% \mathrm{SiC}+6 \% \mathrm{~F}$.A.) which is about $5.27 \%$ improvement on that of Sample2.Table4showsresults of tensile test.

The tensile strength of Sample 2(LM6 $+6 \% \mathrm{SiC}+3 \% \mathrm{~F}$.A.) is $225.053 \mathrm{~N} / \mathrm{mm}^{2}$ and this value increases to a maximum of $276.008 \mathrm{~N} / \mathrm{mm}^{2}$ for Sample3(LM6 $+6 \% \mathrm{SiC}+6 \% \mathrm{~F}$.A.) which is about $22.68 \%$ improvement on that of Sample 2.Table5 showsresults of tensile test.

A Study on Mechanical Properties of Aluminium Alloy (LM6) Reinforced with Sic and Red mud Tensile test is carried out at room temperature using universal testing machine. In this study it can be noted that the addition of Sic and Redmudparticles improved the tensile strength of the composites. It is apparent that an varying in the volume fraction of Sic,Redmudparticle results in an increase in the tensile strength [6]. Graph 4 and graph 5 shows the effect of the weight fraction on the tensile strength and percentage of elongation.

The tensile strength ofSample2 (LM6 $+3 \% \mathrm{SiC}+3 \% \mathrm{R} . \mathrm{M}$ ) is $232.696 \mathrm{~N} / \mathrm{mm}^{2}$ and this value increases to a maximum of $242.038 \mathrm{~N} / \mathrm{mm}^{2}$ for sample 3 (LM6 $+3 \% \mathrm{Sic}+6 \%$ R.M.) which is about $4.02 \%$ improvement on that of sample 2.table 6 shows result of tensile test.

The tensile strength of Sample 2(LM6+6\%SiC+3\%R.M.) is $249.680 \mathrm{~N} / \mathrm{mm}^{2}$ and this value increases to a maximum of $255.053 \mathrm{~N} / \mathrm{mm}^{2}$ for Sample3 (LM6 $+6 \% \mathrm{SiC}+6 \% \mathrm{R} . \mathrm{M}$.) which is about $2.15 \%$ improvement on that of Sample 2.Table7 showsresults of tensile test.

\section{Impact Test (Charpy Test)}

The Charpy impact test, also known as the Charpy v-notch test, is a standardized high strain- rate test which determines the amount of energy absorbed by a material during fracture. This absorbed energy is a measure of a given material's toughness [4].Table 8 and 9 shows results of impact test. From the graph (7) it is clear that energy absorption by metal matrix composite increase gradually as the weight $\%$ of Flyash increases by $3 \%$ and $6 \%$ respectively for constant weight of Sic. From the graph (8) it is clear that energy absorption by metal matrix composite reduces gradually as the weight $\%$ of Redmud increases by 3\%and 6\%,respectively for constant weight of Sic.

\section{Wear Test}

Wear test were carried out at room temperature for $30 \mathrm{~min}$,by keeping load 1.5kg,Disc speed $300 \mathrm{rpm}$, track diameter 65. A cylindrical (sample) pin of size $8 \mathrm{~mm}$ diameter and $22 \mathrm{~mm}$ length hybrid composite specimens were prepared and fixed in a pin on disc wear testing rig as shown in fig.3.before testing, clean the disc and the surface of the specimen was polished by using 1000 grit paper. Wear, the progressive loss of material from the sliding surface of the element of a tribo system can be determined in terms of weight loss. The result of weight loss shown in table 10 and 12. The result of wear, wear rate, wear resistance shown in table 11 and 13. The wear resistance is increased by increase in addition of fly ash in a LM6-Sic hybrid composite. But the addition of redmud in LM6-Sic hybrid composite, the wear resistance decreases.

While comparing composition of LM6 $+3 \% \mathrm{Sic}+6 \%$ flyash and LM6 $+6 \% \mathrm{Sic}+6 \%$ Redmud give the best wear as shown in graph 9 and 11 .

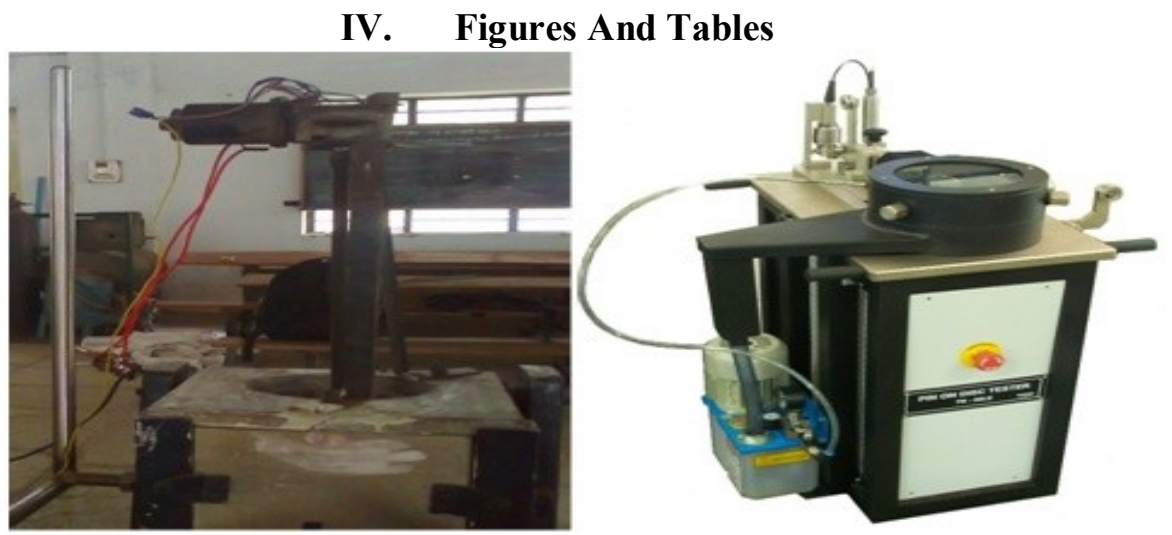

Fig.1 shows stir casting setupFig.2 shows wear test setup 


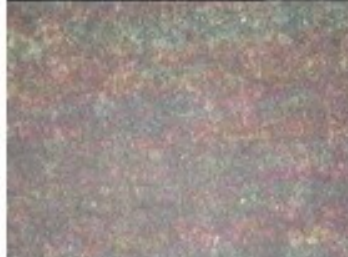

(a) FA1

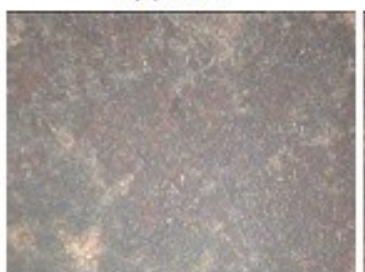

(a) RM 1

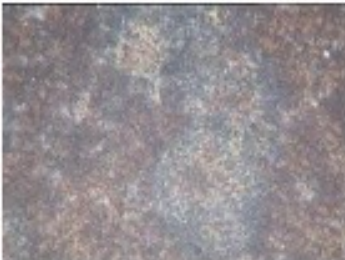

(b) FA 2

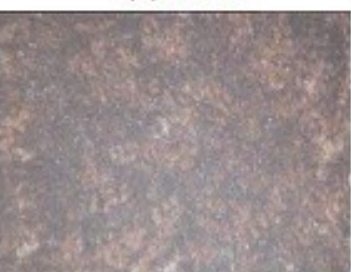

(b) RM 2

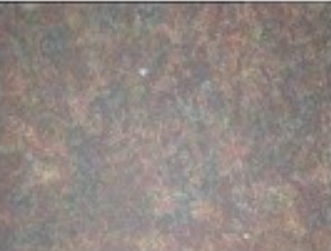

(c)EA 3

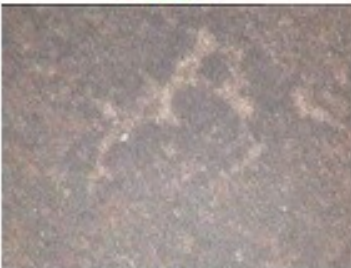

(c) RM 3

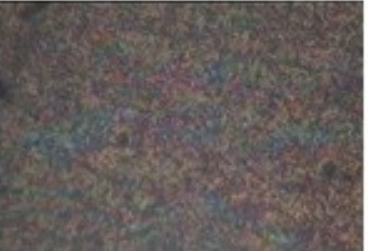

(d)FA 4

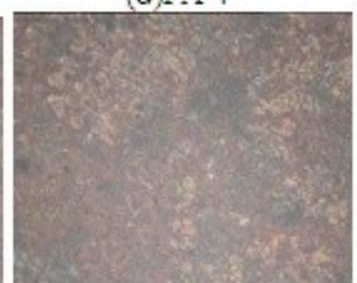

(d) RM 4

Fig 2 shows the microstructure viewed by optical microscope for different weight fraction of HybriumComposite(LM6/Sic/Fly ash/Redmud)

Table 1 Chemical composition of LM6.

\begin{tabular}{|c|c|}
\hline Components & Weight \% \\
\hline Copper & 0.09 \\
\hline Magnesium & 0.06 \\
\hline Silicon & 11.5 \\
\hline Iron & 0.20 \\
\hline Manganese & 0.30 \\
\hline Zinc & 0.07 \\
\hline Aluminium & Remainder \\
\hline
\end{tabular}

Table2 Chemical Composition of F.A.

\begin{tabular}{|c|c|}
\hline Components & Weight \% \\
\hline $\mathrm{SiO}_{2}$ & 44.8 \\
\hline $\mathrm{Al}_{2} \mathrm{O}_{3}$ & 22.2 \\
\hline $\mathrm{Fe}_{2} \mathrm{O}_{3}$ & 24 \\
\hline $\mathrm{MgO}$ & 0.9 \\
\hline $\mathrm{CaO}$ & 1.8 \\
\hline $\mathrm{TiO}_{2}$ & 0.8 \\
\hline $\mathrm{K}_{2} \mathrm{O}$ & 2.4 \\
\hline $\mathrm{Na}_{2} \mathrm{O}$ & 0.9 \\
\hline $\mathrm{SO}_{3}$ & 1.4 \\
\hline \multicolumn{2}{|c|}{$\mathrm{Balance}^{2}$ Oxides of other trace element } \\
\hline \multicolumn{2}{|c}{}
\end{tabular}

Table 3- Chemical Composition of Red Mud in Element and Compound form

\begin{tabular}{|c|c|c|c|}
\hline $\begin{array}{c}\text { Constituents } \\
\text { (Elements) }\end{array}$ & $\begin{array}{c}\% \\
\text { (weight) }\end{array}$ & Constituents(Compound) & \%(Weight) \\
\hline $\mathrm{Al}$ & 7.67 & $\mathrm{Al} 2 \mathrm{O} 3$ & 14.49 \\
\hline $\mathrm{Si}$ & 3.22 & $\mathrm{SiO} 2$ & 6.89 \\
\hline $\mathrm{Ca}$ & 3.67 & $\mathrm{Ca} \mathrm{O}$ & 5.13 \\
\hline $\mathrm{Ti}$ & 12.37 & $\mathrm{Ti} \mathrm{O} 2$ & 20.63 \\
\hline $\mathrm{Fe}$ & 30.70 & $\mathrm{Fe} 2 \mathrm{O} 2$ & 39.49 \\
\hline $\mathrm{Cu}$ & 2.94 & $\mathrm{CuO}$ & 3.68 \\
\hline $\mathrm{Zn}$ & 2.14 & $\mathrm{ZnO}$ & 2.68 \\
\hline $\mathrm{O}$ & 32.09 & & 100 \\
\hline $\mathrm{Total}$ & 100 & $\mathrm{Total}$ & \\
\hline
\end{tabular}

V. Result And Discussion

\section{Tensile Test Result}

Table 4 Results of Tensile Test.

\begin{tabular}{|l|l|l|l|}
\hline Sample & Composition & $\begin{array}{l}\text { Tensile Strength } \\
\left(\mathbf{N} / \mathbf{m m}^{2}\right)\end{array}$ & Elongation(\%) \\
\hline Sample 1 & LM6 & 165.58 & 3 \\
\hline Sample 2 & 165.358 & 2.66 \\
\hline Sample 3 & LM6+3\%SiC+3\%F.A. & 174.097 & 4 \\
\hline
\end{tabular}




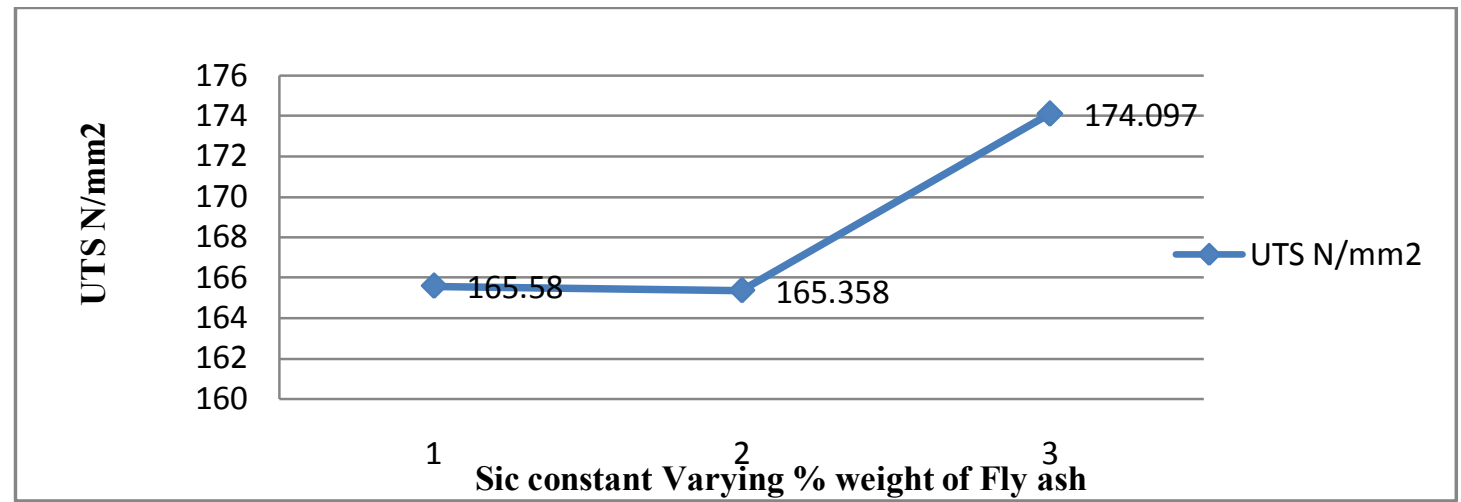

Graph 1 shows the effect of the weight fraction on the UTS.

Table 5 Results of Tensile Test.

\begin{tabular}{|l|c|l|l|}
\hline Sample & Composition & $\begin{array}{l}\text { Tensile Strength } \\
\left(\mathbf{N} / \mathbf{m m}^{\mathbf{2}}\right)\end{array}$ & Elongation(\%) \\
\hline Sample1 & LM6 & 165.58 & 3 \\
\hline Sample2 & LM6+6\%SiC+3\%F.A. & 225.053 & 3.33 \\
\hline Sample3 & LM6+6\%SiC+6\%F.A. & 276.008 & 3.00 \\
\hline
\end{tabular}

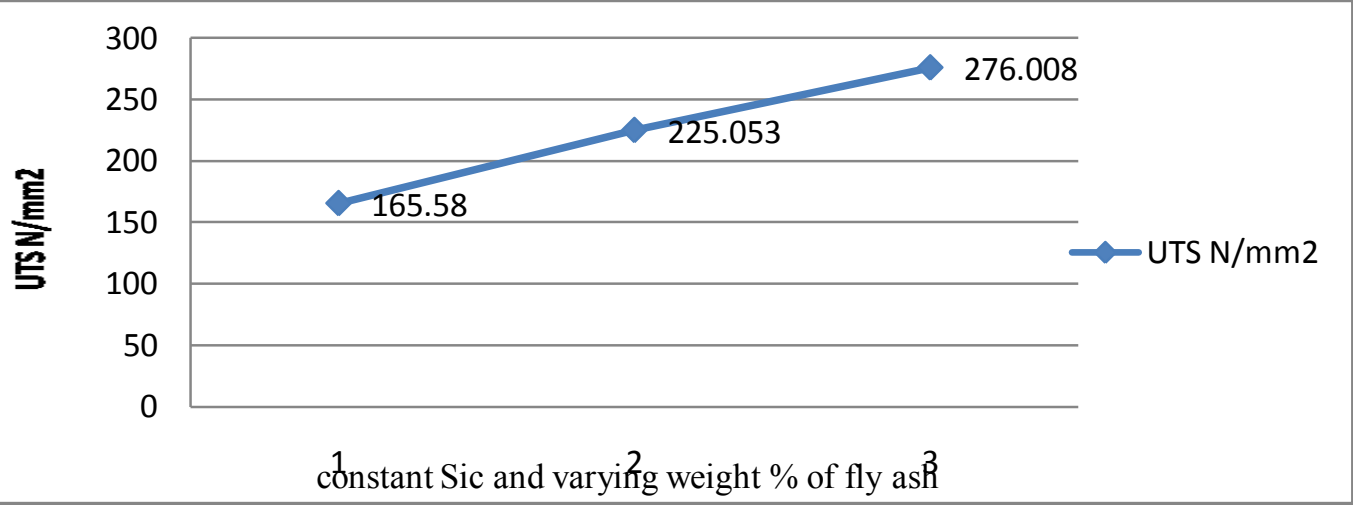

Graph 2 shows the effect of the weight fraction on the UTS.

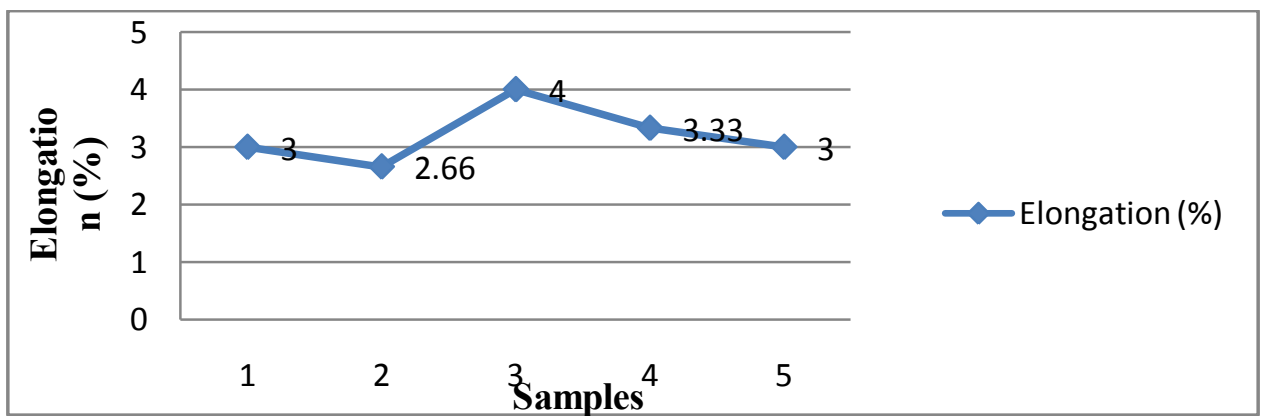

Graph 3 shows the effect of the weight fraction on the \% of Elongation.

Table 6 Results of Tensile Test.

\begin{tabular}{|l|l|l|l|}
\hline Sample & Composition & $\begin{array}{l}\text { Tensile Strength } \\
\left(\mathbf{N} / \mathbf{m m}^{2}\right)\end{array}$ & Elongation (\%) \\
\hline Sample 1 & 165.58 & 3 \\
\hline Sample 2 & LM6 & 232.696 & 4 \\
\hline Sample 3 & LM6+3\%SiC+3\%R.M. & 242.038 & 5.33 \\
\hline
\end{tabular}


A Study on Mechanical Properties of Aluminium Alloy (Lm6) Reinforced With Fly Ash, Redmud ....

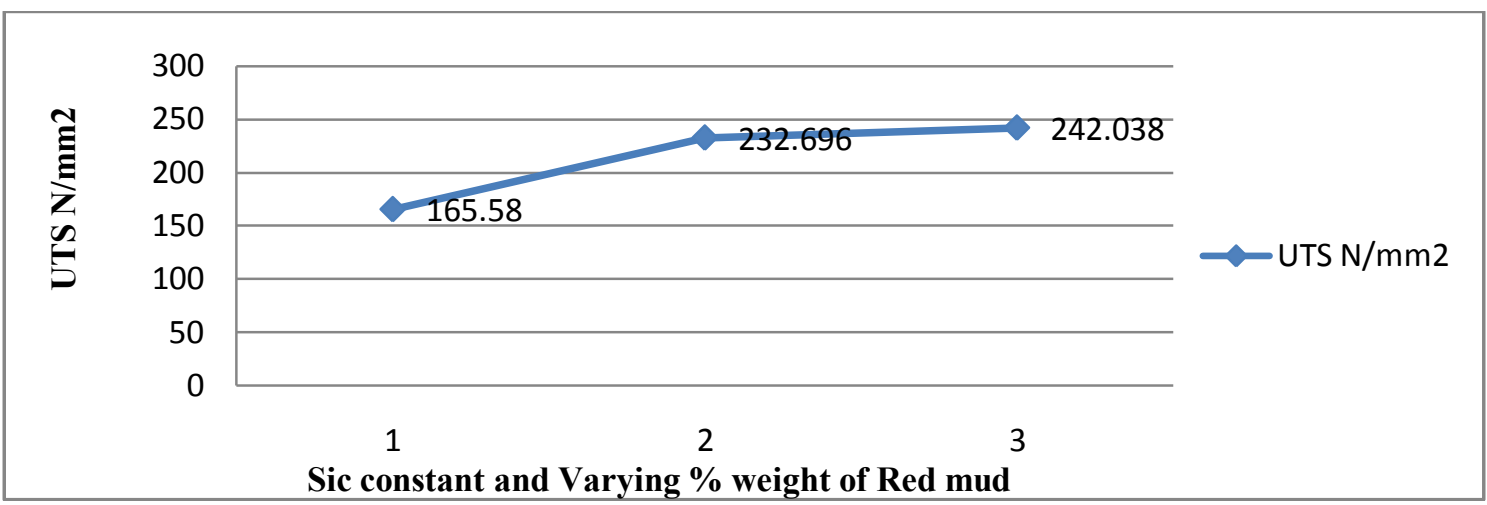

Graph 4 shows the effect of the weight fraction on the UTS.

Table 7 Results of Tensile Test.

\begin{tabular}{|c|c|c|c|}
\hline Sample & Composition & Tensile Strength $\left(\mathrm{N} / \mathrm{mm}^{2}\right)$ & Elongation (\%) \\
\hline Sample1 & LM6 & 165.58 & 3 \\
\hline Sample2 & LM6+6\%Sic $+3 \%$ R.M. & 249.680 & 4 \\
\hline Sample3 & LM6+6\%Sic $+6 \%$ R.M. & 255.053 & 2.66 \\
\hline
\end{tabular}

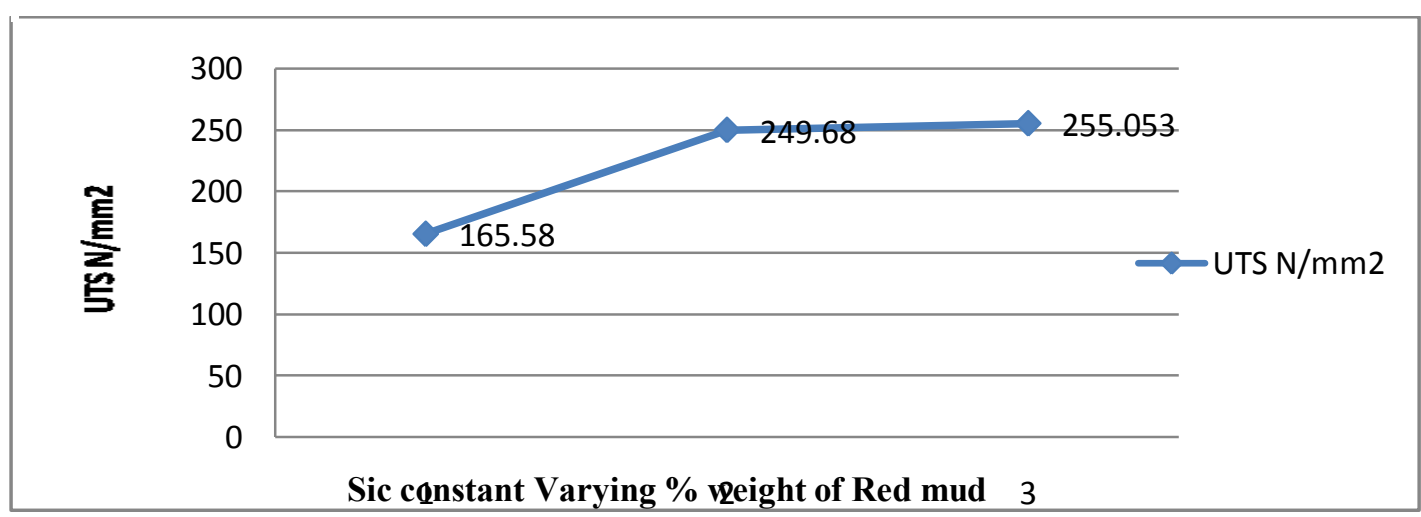

Graph 5 shows the effect of the weight fraction on the UTS.

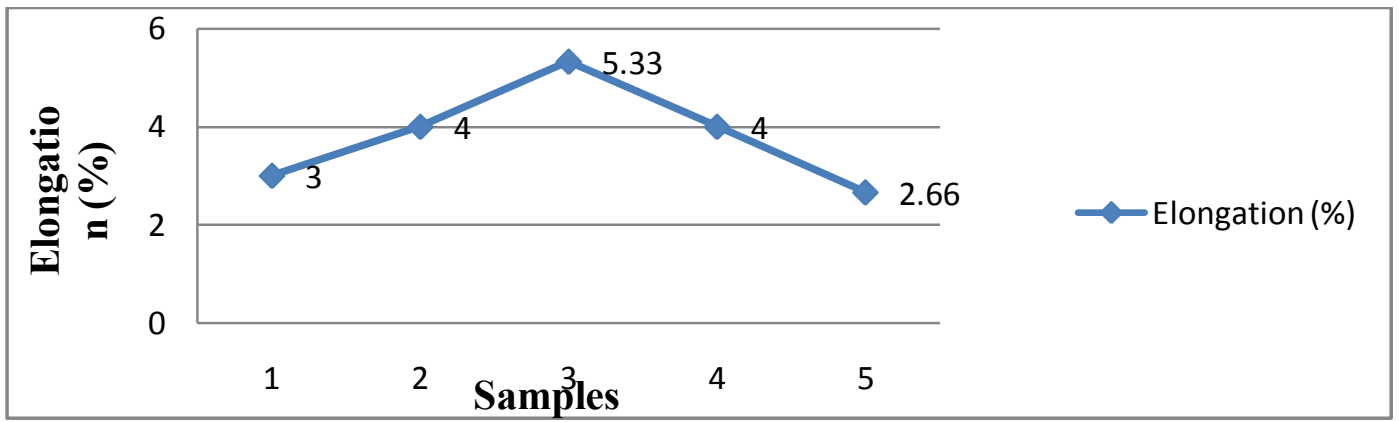

Graph 6 shows the effect of the weight fraction on the \% of Elongation.

Table 8 Results of Impact Test

\begin{tabular}{|l|l|l|}
\hline Sample & Composition & Energy Absorbed kg-m \\
\hline Sample 1 & LM6 & 5.6 \\
\hline Sample 2 & LM6+3\%SiC+3\%F.A. & 4.8 \\
\hline Sample 3 & LM6+3\%SiC+6\%F.A. & 5.1 \\
\hline Sample4 & LM6+6\%SiC+3\%F.A. & 6.0 \\
\hline Sample5 & LM6+6\%SiC+6\%F.A. & 6.6 \\
\hline
\end{tabular}




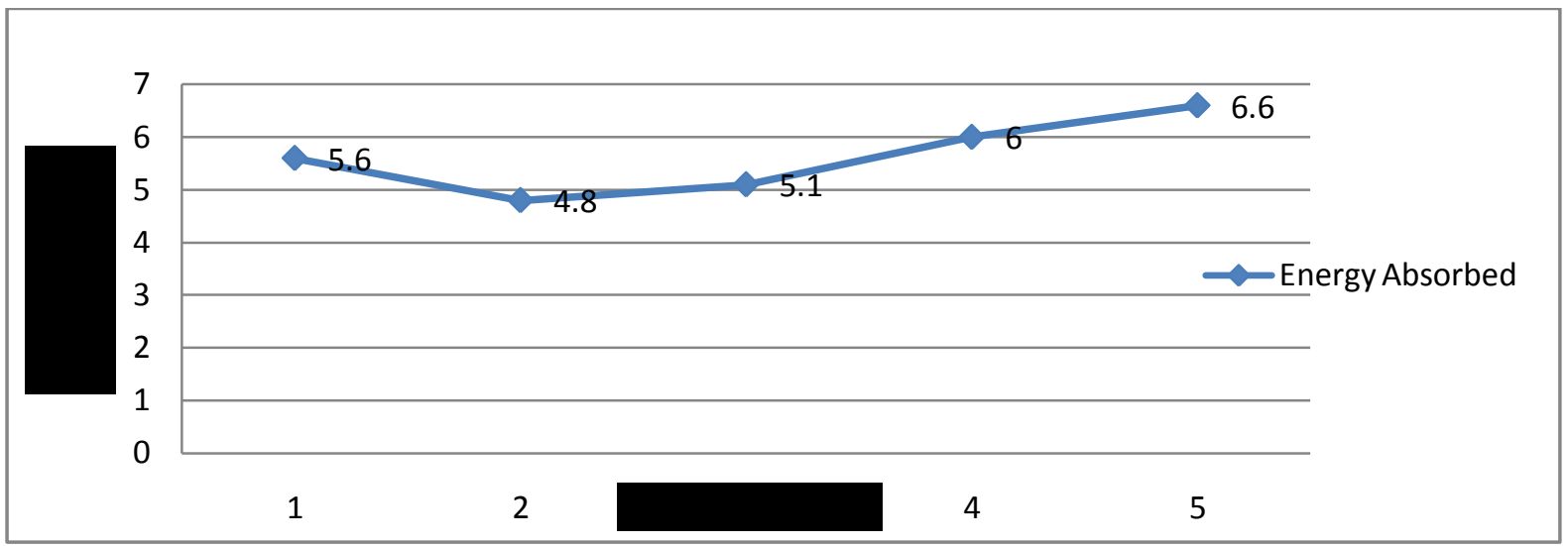

Graph 7 shows the effect of the weight fraction on energy absorbed by specimen.

Table 9 Results of Impact Test

\begin{tabular}{|l|l|c|}
\hline Sample & Composition & Energy Absorbed kg-m \\
\hline Sample 1 & LM6 & 5.6 \\
\hline Sample 2 & LM6+3\%SiC+3\%R.M. & 4.0 \\
\hline Sample 3 & LM6+3\%SiC+6\%R.M. & 4.5 \\
\hline Sample4 & LM6+6\%SiC+3\%R.M. & 4.6 \\
\hline Sample5 & LM6+6\%SiC+6\%R.M. & 5.3 \\
\hline
\end{tabular}

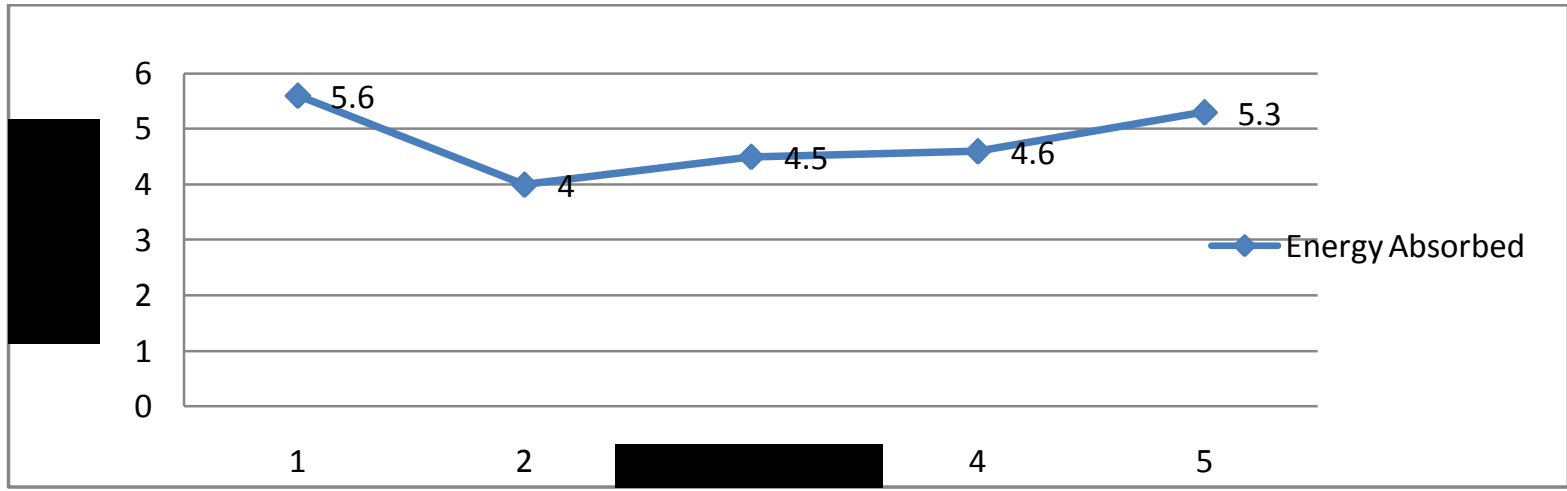

Graph 8 shows the effect of the weight fraction on energy absorbed by specimen.

Table 10 shows the result of wear test by keeping Load 1.5kg, Time 30min.,\& Disc Speed 300RPM, Disc diameter 65

\begin{tabular}{|c|c|c|c|c|}
\hline Sample No & Composition & Initial weight in gm & Final weight in gm & Weight loos in gm \\
\hline 1 & LM6+3\%SiC+3\%F.A. & 2.95245 & 2.94256 & 0.00989 \\
\hline 2 & LM6+3\%SiC+6\%F.A. & 3.1162 & 3.10587 & 0.01033 \\
\hline 3 & LM6+6\%SiC+3\%F.A. & 3.06223 & 3.04984 & 0.01239 \\
\hline 4 & LM6+6\%SiC+6\%F.A. & 2.91029 & 2.90125 & 0.00904 \\
\hline
\end{tabular}

Table 11 shows the result of wear rate and wear resistance by keeping load $1.5 \mathrm{~kg}$,time $30 \mathrm{~min}$ and Disc speed 300 , Disc diameter 65

\begin{tabular}{|c|c|c|c|c|}
\hline Sample No & Composition & Wear in $\mu \mathrm{m}$ & Wear rate in $\mathrm{mm}^{3} / \mathrm{m}$ & Wear resistance in $\mathrm{m} / \mathrm{mm}^{3}$ \\
\hline 1 & LM6+3\%SiC+3\%F.A. & 184.64 & $5.032 \times 10^{-3}$ & 198.728 \\
\hline 2 & LM6+3\%SiC+6\%F.A. & 381.99 & $10.420 \times 10^{-3}$ & 95.969 \\
\hline 3 & LM6+6\%SiC+3\%F.A. & 214.73 & $5.852 \times 10^{-3}$ & 170.88 \\
\hline 4 & LM6+6\%SiC+6\%F.A. & 121.81 & $3.309 \times 10^{-3}$ & 302.169 \\
\hline
\end{tabular}




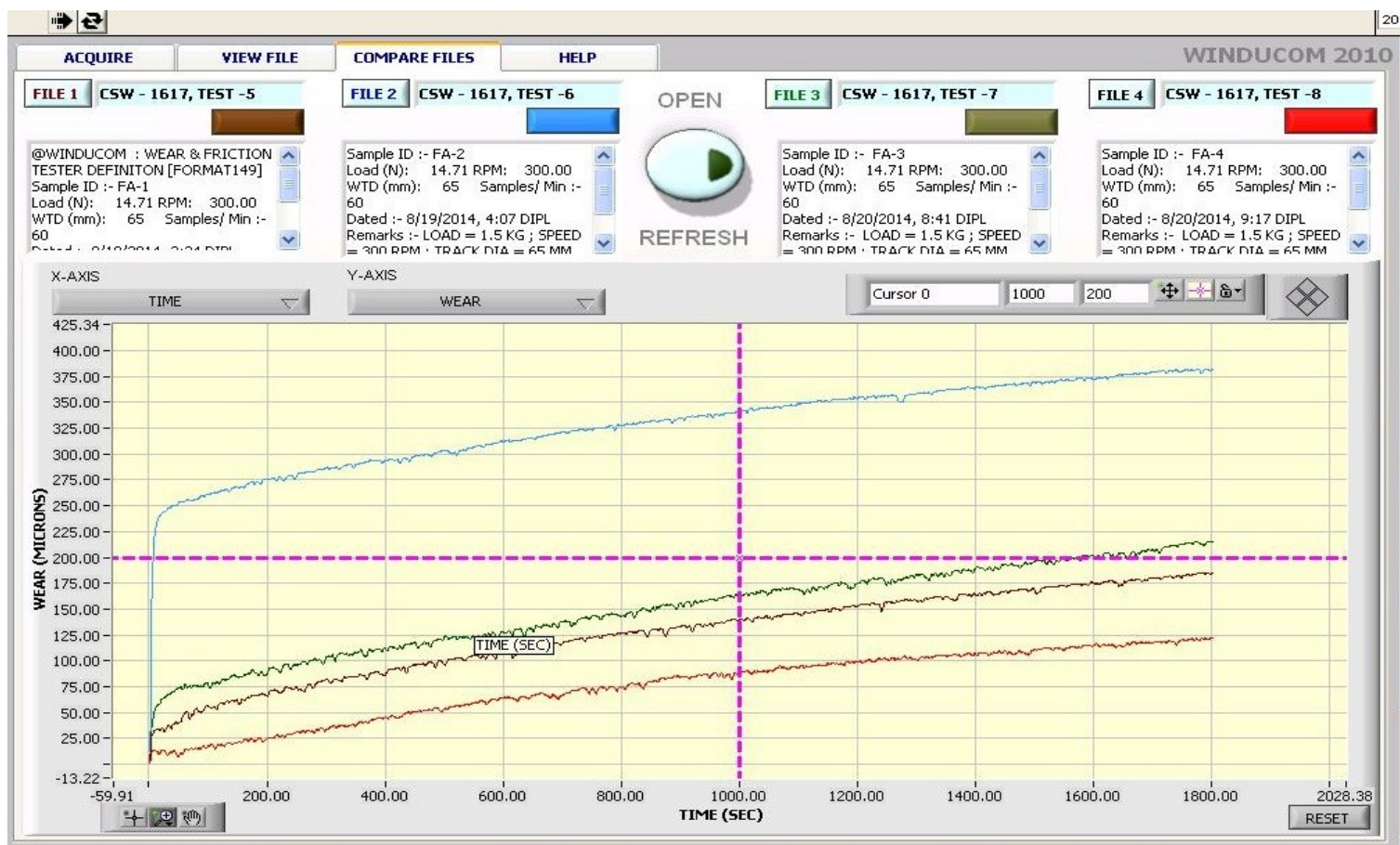

Figure 9 shows the wear comparison graph of all the sample

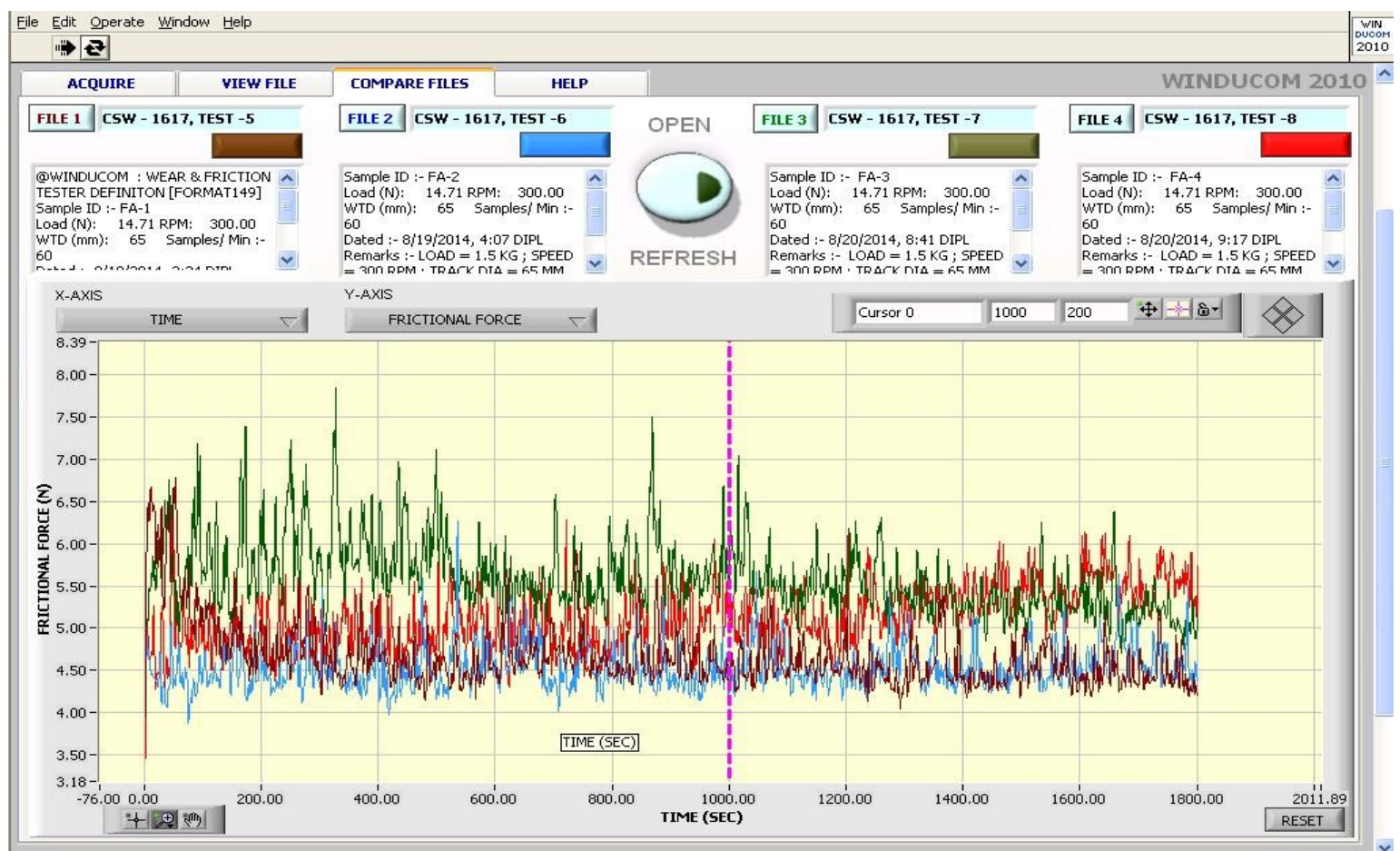

Figure 10 shows the frictional force comparison graph of all the sample

Table 12 shows the result of wear test by keeping load $1.5 \mathrm{~kg}$, time $30 \mathrm{~min}$, and Disc speed 300RPM, Disc diameter 65

\begin{tabular}{|c|c|c|c|c|}
\hline Sample No & Composition & Initial weight in gm & Final weight in gm & Weight loos in gm \\
\hline 1 & LM6+3\%SiC+3\%R.M & 2.94846 & 2.94161 & 0.00685 \\
\hline 2 & LM6+3\%SiC+6\%R.M & 2.90809 & 2.90174 & 0.00635 \\
\hline 3 & LM6+6\%SiC+3\%R.M & 2.85046 & 2.84456 & 0.0059 \\
\hline 4 & LM6+6\%SiC+6\%R.M & 3.23729 & 3.22824 & 0.00905 \\
\hline
\end{tabular}


A Study on Mechanical Properties of Aluminium Alloy (Lm6) Reinforced With Fly Ash, Redmud ....

Table 13 shows the result of wear rate and wear resistance by keeping load $1.5 \mathrm{~kg}$,time $30 \mathrm{~min}$ and Disc speed 300, Disc diameter 65

\begin{tabular}{|c|c|c|c|c|}
\hline Sample No & Composition & Wear in $\mu \mathrm{m}$ & Wear rate in $\mathrm{mm}^{3} / \mathrm{m}$ & Wear resistance in m/mm $\mathrm{m}^{3}$ \\
\hline 1 & LM6+3\%SiC+3\%R.M & 178.44 & $4.70 \mathrm{X} 10^{-3}$ & 212.58 \\
\hline 2 & LM6+3\%SiC+6\%R.M & 242.76 & $6.61 \mathrm{X} 10^{-3}$ & 151.08 \\
\hline 3 & LM6+6\%SiC+3\%R.M & 169.86 & $4.621 \mathrm{X} 10^{-3}$ & 216.40 \\
\hline 4 & LM6+6\%SiC+6\%R.M & 243.52 & $6.646 \times 10^{-3}$ & 150.46 \\
\hline
\end{tabular}

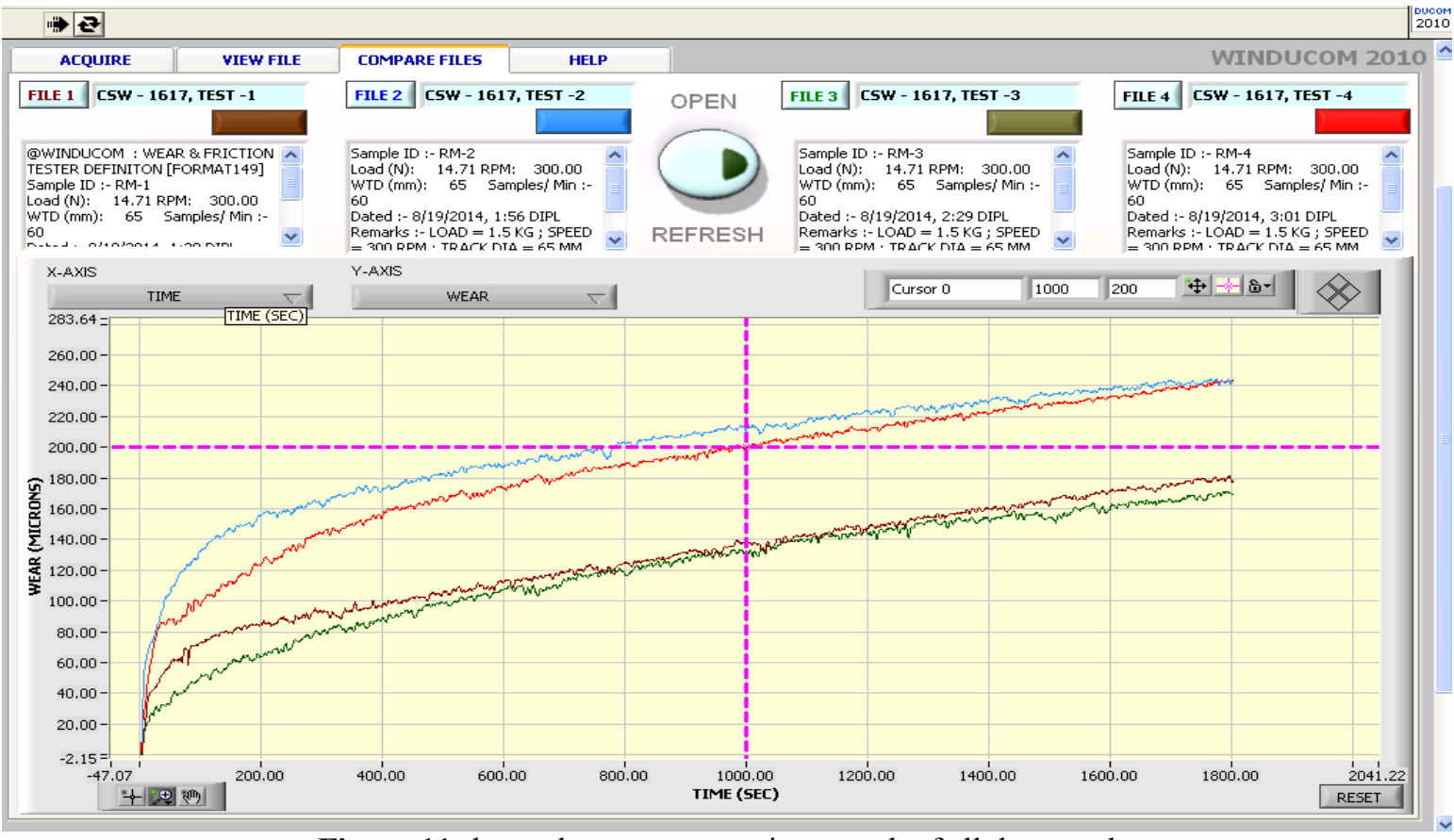

Figure 11 shows the wear comparison graph of all the sample

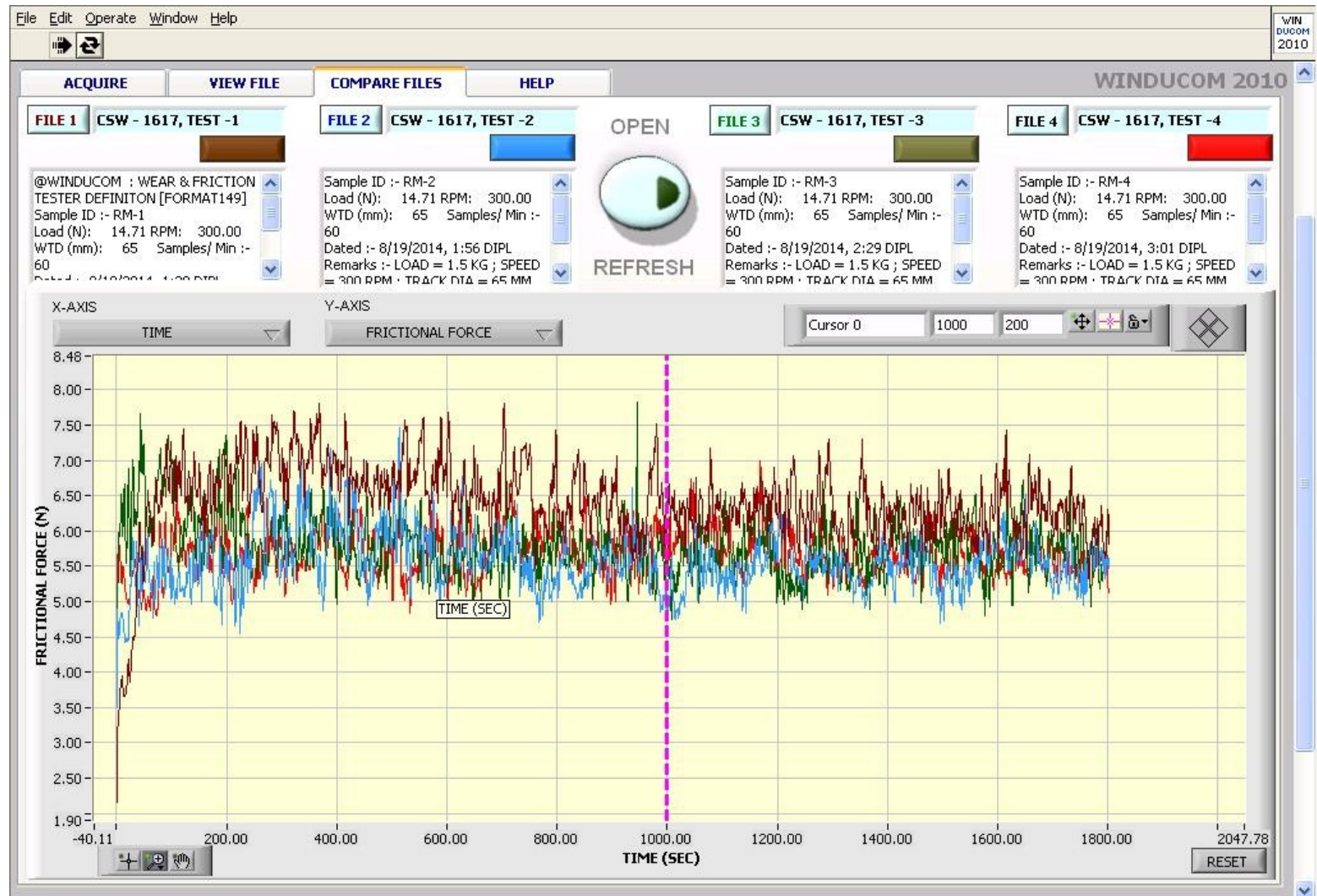

Figure12 shows the frictional force comparison graph of all the sample 


\section{Conclusion}

1) LM6 based hybrid composite up to $6 \%$ of fly ash and redmud have been successfully fabricated by stir casting technique.

2) The microstructure study shows that Sic, redmud and fly ash are fairly uniform distribution of Sic, redmu and fly ash in LM6 based metal matrix composite.

3) In this study the tensile strength starts increase with increase in weight percentage of fly ash and red mud.

4) In this study it is found that elongation tends to decrease with increasing weight percentage flyash and redmudwhich confirms that the addition of Sic, red mud and fly ash increase the brittleness.

5) The impact strength of the hybrid composite increases with increases in weight percentage of fly ash. But the impact strength of hybrid composite decreases with increase in weight percentage of redmud.

6) It appears from this study the wear resistance tends to increase with increase in addition of fly ash and red mud in LM6-Sic hybrid composite.

7) $\mathrm{LM} 6+6 \% \mathrm{Sic}+6 \% \mathrm{~F}$.A. shows the better wear resistance when compared with other samples.

8) LM6+6\% $\mathrm{Sic}+3 \%$ R.M. shows the better wear resistance when compared with other samples.

9) From this study it is concluded that we can use fly ash for the production of composites.

10) From the study it reveals that Sic+Flyash is giving better results when compared with Sic+Redmud. So that we can use flyash for the production of composites.

\section{References}

[1]. MahendraBoopathi, M., K.P. Arulshri and N. Iyandurai, Evaluation of Mechanical properties of Aluminium alloy 2024 reinforced with Silicon Carbide and Fly ash hybrid metal matrix composites, American Journal of Applied Sciences, 10 (3): 219-229, 2013.

[2]. Mr. Amol D. Sable1, Dr. S. D. Deshmukh,Preparation of metal matrix composites by stir casting method, International Journal of Mechanical Engineering and Technology, Volume 3, Issue 3, September - December (2012), pp. 404-41.

[3]. Basavaraju.SArasukumar.KDr.ChandrashekharBendigeriDr.C.K.Umesh, Studies on Mechanical Properties and Tribological Characteristics of LM25- Graphite- Silicon Carbide and LM25-Flyash- Silicon Carbide - Hybrid MMC's,International Journal of Innovative Research in Science, Engineering and Technology Vol. 1, Issue 1, November 2012.

[4]. H.C. Anilkumar, H.S. Hebbar and K.S. Ravishankar, Mechanical properties of Fly ash reinforced Aluminium alloy(Al6061) composites,International Journal of Mechanical and Materials Engineering (IJMME), Vol.6 (2011), No.1, 41-45.

[5]. Shanmughasundara, R. Subramanian and G. Prabhu, Some Studies on Aluminium - Fly ash Composites Fabricated by Two Step Stir Casting Method,European Journal of Scientific Research,ISSN 1450-216X Vol.63 No.2 (2011), pp.204-218.

[6]. Er. Sandeep Kumar Ravesh, Dr. T. K. Garg, Preparation \& Analysis for some mechanical property of Aluminium based metal matrix composite reinforced with SiC\& Fly ash, International Journal of Engineering Research and Applications, Vol. 2, Issue 6, November- December 2012, pp.727-731

[7]. Sankar.L, Srinivasan.R, Viswanathan.P and Subramanian.R ,Comparison study of Al-Fly ash composites in automobile clutch plates, International Journal of Emerging trends in Engineering and Development, Issue 3, Vol.3 (May 2013).

[8]. J. Babu Rao, D. Venkata Rao and N.R.M.R. Bhargava ,Development of light weight ALFA composites, International Journal of Engineering, Science and Technology Vol. 2, No. 11, 2010, pp. 50-59. 